\title{
Analysis and Prospect of China's Corn Production Cost Status
}

\author{
Hao Zhang \\ School of Economics and Management, Zhejiang Ocean University, Zhoushan, Zhejiang, 316022, China
}

\begin{abstract}
Using the relevant data from the National Bureau of Statistics of China from 1970 to 2018, it can be found that China's corn sown area and yield have maintained steady growth, but through research and analysis of China's corn output value and various production cost data from 2014 to 2018, agricultural producers are operating at a loss. The low profit or even loss of corn planting will discourage agricultural producers from planting corn, which is not a good trend. Based on the review of relevant research literature on maize in China, and the analysis of various production costs from 2014 to 2018 , this paper attempts to propose countermeasures to reduce various production costs without affecting the stable growth of maize sown area and yield. Help Chinese corn develop well in the future.
\end{abstract}

Keywords: Corn, Cost of production, Cost net profit, Outlook.

\section{Introduction}

Corn is one of the three major food crops in China (rice, wheat and corn). The sown area has been ranked first since 2007. In 2020 , the sown area of corn is 41,260 thousand hectares, which is 1.37 times the sown area of rice and the sown area of wheat. 1.76 times that of the three major grain crops, equivalent to $44 \%$ of the sown area of the three major grain crops. Corn also plays an important role in China's global trade in agricultural products. From 2017 to 2019, China's corn imports continued to grow. In 2019, China imported 4.8 million tons of corn. Based on the current domestic situation, especially the invasion of natural disasters in 2021, China's corn imports will continue to rise. Corn has an important voice in China's food security issues. At present, under the background of limited agricultural resources in China, agricultural producers all hope to obtain maximum benefits in the production process. Therefore, discussing the cost-benefit issue of corn can not only find unreasonable points, but also improve the economic benefits of agricultural producers to a certain extent. Improve the enthusiasm for planting corn, promote the sound and sustainable development of China's corn industry, and ensure China's national food security issues.

\section{Analysis on the Status Quo of Maize Production in China}

In the 1970s, China's corn sown area was second only to wheat and rice. In recent years, due to high yield and strong adaptability, the corn sown area has continued to rise and far exceeds that of wheat and rice. According to the statistics of the National Bureau of Statistics[1], the corn planting area in China has increased from $15,831.3$ thousand $\mathrm{hm}^{2}$ in 1970 to 41,260 thousand $\mathrm{hm}^{2}$ in 2020, and the annual output has continued to increase from 114.0877 million $t$ in 2001 to 260.67 million $t$ in 2020 . While corn acreage and production yields continued to rise, there was little change in average yield per hectare. In the current situation of rising production costs, the price of corn has been at a low level, which has led to a decrease in the economic benefits of farmers planting corn. The production costs and output values of the maize planting process in the country from 2014 to 2018 are shown in Table 1.
Table 1: Various production costs and output values of corn

\begin{tabular}{|c|c|c|c|c|c|}
\hline \multicolumn{1}{c}{ in China from 2014 to 2018 } & \multicolumn{2}{r|}{ unit: yuan } \\
\hline Year & 2014 & 2015 & 2016 & 2017 & 2018 \\
\hline Seed cost & 55.24 & 56.82 & 56.56 & 55.44 & 55.72 \\
\hline Fertilizer cost & 141.70 & 142.38 & 138.52 & 142.98 & 150.59 \\
\hline Pesticide cost & 15.02 & 16.61 & 16.22 & 16.69 & 17.12 \\
\hline $\begin{array}{c}\text { Mechanical } \\
\text { operation cost }\end{array}$ & 105.11 & 111.98 & 114.43 & 116.73 & 117.27 \\
\hline $\begin{array}{c}\text { Irrigation and } \\
\text { drainage cost }\end{array}$ & 21.69 & 21.53 & 17.59 & 17.47 & 17.41 \\
\hline \begin{tabular}{c} 
Cost of labor \\
\hline Land cost
\end{tabular} & 474.68 & 468.72 & 458.10 & 441.20 & 433.52 \\
\hline Other costs & 26.04 & 26.90 & 26.23 & 25.67 & 25.65 \\
\hline $\begin{array}{c}\text { Total cost } \\
\text { Total value of } \\
\text { out-put }\end{array}$ & 1145.71 & 949.54 & 765.89 & 850.69 & 881.48 \\
\hline
\end{tabular}

Note: (1) The data are the cost and output value per $1 / 15 \mathrm{hm}^{2}$ of land. Source: National Agricultural Product Cost and Benefit Data Compilation $2019[2]$.

According to Table 1, it can be seen that the total cost of corn in my country from 2014 to 2018 did not change much as a whole, showing a process of rising, falling and then rising. Among them, the gross output value dropped sharply in 2016. The reason is that the price of corn dropped sharply that year. On the one hand, my country carried out the structural reform of the agricultural supply side at that time. The new measures of separation of price and compensation have greatly reduced the enthusiasm of agricultural producers to plant corn, and many agricultural producers have given up planting corn areas to grow other crops[3]. The cost of chemical fertilizers and mechanical operation costs are rising every year. The increase in the cost of chemical fertilizers is due to the gradual decrease in the use of farmyard manure, the increase in the use of chemical fertilizers developed by technology, and the increase in the cost of mechanical operation. cost plays an increasingly important role. The labor cost has been decreasing year by year, which shows that due to the continuous development of technology, mechanical operations have gradually replaced manual operations. The analysis of the net cost of corn in my country from 2014 to 2018 is shown in Figure 1. 


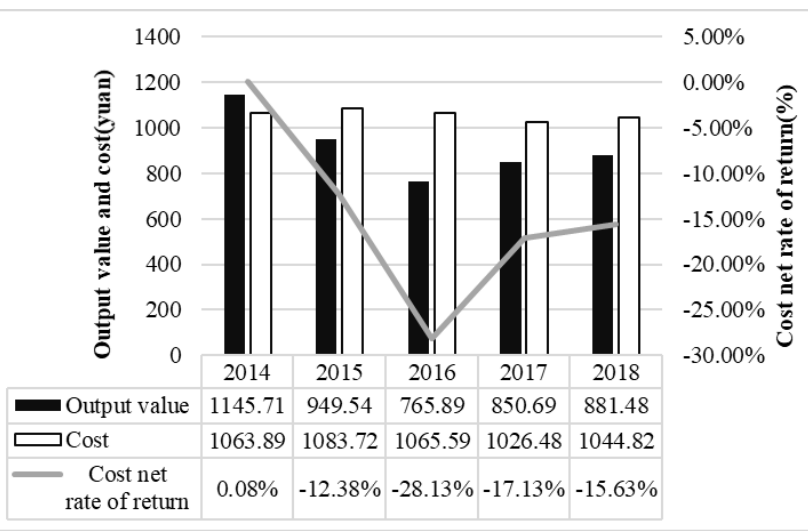

Figure 1: Analysis of China's corn cost net yield from 2014 to 2018

Note: (1) The data are the cost, output value and cost net rate of return per $1 / 15 \mathrm{hm}^{2}$ of land; $(2)$ Cost pure rate of return $=($ production value $-\operatorname{cost}) /$ cost $\times 100 \%$.

Source: Compiled from the National Agricultural Product Cost and Benefit Data Compilation 2019[2].

It can be seen from Figure 1 that the net yield of corn cost in my country in 2014 was $0.08 \%$, that is, it was just planted without loss, but there was no profit at all. From 2015 to 2018, the net cost and return rate were all negative, that is, planting at a loss. Among them, the net cost yield in 2016 was the lowest value of $-28.13 \%$. From 2017 to 2018, the net cost yield gradually improved but also continued to lose money. The economic benefits obtained from planting food crops can only be changed through three aspects: output, price and cost. On the basis of little change in output and no change in price, agricultural producers can only seek to increase economic benefits by reducing production costs.

\section{Question}

The low economic benefits obtained by agricultural producers from planting corn is a threshold that affects the modernization of China's corn. In order to reduce production costs and improve economic benefits, they must start from all aspects of the planting process. The most basic cost is corn seeds, planting process. The required fertilizers, pesticides, irrigation water, and other costs of machinery, labor, and land.

First, seeds are the basis of crops. There are roughly two points in the seed problem. The first point is that there is still a certain gap in the research technology of new varieties of corn seeds in China compared with other countries. The main reason is the lack of stable scientific research institutions and a professional scientific research team. It is the foundation of technological development and innovation. The second point is that China's corn development is large-scale, modernized and industrialized, the market size is gradually expanding, and the competition is fierce. It is also worth thinking about how to better protect new corn varieties[4]. Secondly, the current cost of chemical fertilizers and pesticides for corn is relatively high. The main reason is that the amount of pesticides and chemical fertilizers used in my country has surged since the 21 st century. On the one hand, farmers hope to use more pesticides to improve the health of wheat, thereby increasing production. Secondly, there is a serious outflow of young labor force in my country's rural areas, and the number of elderly people and left-behind children in rural areas is increasing rapidly. As a result, there is a shortage of personnel to take care of wheat crops. Therefore, the use of pesticides has to be increased to make up for the shortage of personnel[5]. Fertilize, use less organic fertilizer. At present, most of the areas where corn is grown in China have backward irrigation methods. In rural areas, flood irrigation is still used for corn cultivation. The backward irrigation method will not only cause a lot of waste of agricultural water resources, but also increase the production cost of farmers. Water-saving irrigation facilities in my country are seriously insufficient and rarely maintained, resulting in the aging of most facilities. Compared with the past, mechanical operations have been much better, but compared with other countries, there are still many problems. In the process of actual agricultural modernization, due to factors such as the backward thinking of farmers, the backwardness of rural economy and the use of agricultural machinery, agricultural. The promotion and application effect of mechanization is not ideal[6]. Second, the mechanical operation of corn in China started late, with backward technological development and poor mechanical performance, which is prone to failure. Once a failure occurs, maintenance will take a lot of time. In recent years, my country's economy has developed rapidly, people's living standards have continued to improve, and incomes have also continued to rise. Of course, there are agricultural labor forces. The people engaged in agricultural labor are basically rural people, and the government has been trying to improve the income of rural people, but this also increases the expenditure of agricultural labor costs[7]. Finally, the small-scale peasant economy is a stumbling block in the process of large-scale modernization of China's agriculture. Most of the agricultural producers are self-employed, small in scale, low in organization, and weak in the competitiveness of agricultural products. The land is scattered, and it is impossible to implement large-scale planting. Manual work is carried out, which will also increase the production cost to a certain extent.

\section{Suggestion}

There The first is that the government should further improve the market access system, strengthen the supervision of enterprise qualifications, seed quality, and seed varieties, clarify specific responsibilities, restrain unscrupulous merchants in the seed market, and reduce farmers' losses. The second is that enterprises should increase investment in scientific research, improve scientific and technological innovation capabilities, vigorously introduce excellent scientific research talents for breeding[8], strengthen scientific research cooperation between enterprises and universities, and strengthen intellectual property talent training and technical training. All sectors of society must accelerate the pace of scientific research, create efficient and environmentally friendly fertilizers, and improve the utilization rate of fertilizers, which not only reduces the cost of corn production, but also maintains the sustainable use of arable land. The third is to strengthen publicity. More use of chemical fertilizers and pesticides is not necessarily a lot, but will affect the normal growth of crops. Usually, more organic fertilizers should be used, and technologies such as precise fertilization and precise pesticide spraying should be vigorously promoted. Precision variable technology is an indispensable part of agricultural modernization. This technology can be sown according to the seeding rate required 
by the agronomic requirements of different crops. Seed costs and labor costs, which not only increase economic benefits, but also ensure the sustainable development of agriculture. Fourth, the government vigorously builds farmland infrastructure, learns from other agricultural developed countries, and vigorously promotes water-saving irrigation methods such as drip irrigation and sprinkler irrigation. The fifth is to improve the quality of agricultural machinery. According to the production characteristics of each region, we will design, produce and develop agricultural machinery products with strong practicability that meet the needs of the region, and improve the performance and reliability of the products. Increase government support and encourage financial subsidies to be tilted towards the purchase of corn machinery. Increase publicity efforts to increase farmers' enthusiasm for purchasing corn production machinery [9]. The sixth is to provide policy guidance for farmers with less arable land, encourage reasonable land contracting, and establish agricultural cooperatives to solve the problem of land scale. Through the development of new business entities such as family farms, large grain growers, professional cooperatives and joint-stock cooperatives, etc., a large number of surplus labor in rural areas will be released, and the market for the transfer of rural land management rights will be gradually improved to provide conditions for large-scale corn planting. Large-scale planting is conducive to centralized technical guidance and services, is conducive to reducing costs, improving efficiency, and facilitates corn processing and purchases nearby[10].

\section{Outlook}

The latest Central No. 1 document pointed out that in 2021, China's rural areas should further promote the structural reform of the agricultural supply side. By 2025, the rural production mode will undergo green transformation, the use of chemical fertilizers and pesticides will continue to decline, and farmers' sense of happiness, gain, and security will be significantly improved[11]. It can be seen that with the continuous attention and development of my country's agricultural industry in the future, the situation of high cost and low income of wheat crops will be greatly improved. For a long time, my country has been pursuing the development of the corn industry too much to increase production and not paying enough attention to production costs. Although this direction is reasonable from a certain period of time. However, since the current industrial development problem has shifted from insufficient production capacity to reducing costs and improving efficiency, relevant directions and thinking need to be adjusted and optimized. At present, the more appropriate direction is to find ways to reduce input, reduce costs and increase profits when pursuing a certain output[12]. Reasonably reducing production costs, from a small level, improves the economic benefits of farmers planting wheat, from a large level, it maintains my country's food security under the current international situation, stabilizes social development, and promotes rural development. The revitalization process also protects the ecological environment, reduces waste of water resources, land pollution, groundwater pollution and so on.

\section{References}

[1] National Bureau of Statistics of the People's Republic of China. Annual Data[EB/OL]. https://data.stats.gov.cn/easyquery.htm?cn=C01.

[2] Price Department of National Development and Reform Commission. Compilation of National Agricultural Products Cost and Benefit 2019[M]. China Price Publishing House, 2002.

[3] Xi Yinsheng, Yang Li, Wu Tianlong. Analysis of China's Corn Market in 2016 and Outlook for 2017[J]. Agricultural Outlook, 2017, 13(04): 4-9+14

[4] Yang Haitao, Zhao Jiuran, Yang Fengling, Wang Fengge, Song Wei, Chen Hong. Current situation, problems and suggestions of protection of maize variety rights in my country[J]. Seed, 2015, 34(09): 71-73+76.

[5] Zhao Qianqian. Research on the current situation and problems of pesticide use in China's main food crops[D]. Beijing Institute of Technology, 2015.

[6] Li Hongzeng. Problems and countermeasures in the development of agricultural machinery automation[J]. Southern Agricultural Machinery, 2020, 51(21): 49-50.

[7] Zhong Funing. A correct understanding of food security and agricultural labor costs[J]. Agricultural Economic Issues, 2016, 37(01): 4-9+110.

[8] Dong Xue, Ge Liqun, Cui Ying. Research on the development of corn seed industry in my country $[\mathrm{J}]$. Horticulture and Seedlings, 2016(02): 32-33.

[9] Yao Yongxiang, Liu Xiaoxin, Chen Ruilin, Xia Ruiqi, Jing Xiaopeng, Wang Xiaojie. Problems and countermeasures in the development of maize production mechanization in my country[J]. Agricultural Science and Technology and Equipment, 2013(10): 72-73.

[10] Fan Shaoling. Research on the cost and benefit of corn planting in China[D]. Shandong Agricultural University, 2014.

[11] The Central Committee of the Communist Party of China. The State Council's Opinions on Comprehensively Promoting Rural Revitalization and Accelerating Agricultural and Rural Modernization[EB/OL]. (2021-01-04)[2021-05-07]. http://www.gov.cn/zhengce/2021-02/21/content_55880 98.htm.

[12] Xu Zhigang, Zhang Shihuang. My country's corn industry security issues and development strategies under the new normal[J]. Agricultural Economics and Management, 2017(01): 12-16+35.

\section{Author Profile}

Hao Zhang (1996-), Graduate student at the School of Economics and Management, Zhejiang Ocean University. Born in Pingxiang County, Xingtai City, Hebei Province, professional name is rural development. The research direction is agricultural and rural development planning. 